\title{
A CORPUS-ASSISTED CRITICAL DISCOURSE ANALYSIS OF MODALITY IN SOCIAL TRANSFORMATION CAMPAIGNS IN NIGERIA
}

\author{
Mohammed Ayodeji Ademilokun
}

\begin{abstract}
This article examines modal resources in the mediatised discourse of social transformation in Nigeria with a view to showing how they are strategically used to code interpersonal meanings for enhanced and impactful delivery of messages of social transformation in the nation. Data for the study comprises texts on aspects of social transformation campaigns in Nigeria in the context of democracy, anti-corruption crusade, insecurity and domestic violence compiled as small corpora. The data comprises texts produced by government and non-governmental actors consisting of speeches, radio commentaries, jingles, printed texts, interviews, tweets and online newspaper comments and covers the period from March 2013 to March 2018. The five-year span was informed by the wide gamut of negative realities in the nation during the time frame which led to increased mediatisation of social transformation messages. Corpus-assisted critical discourse approach was employed for data analysis, using Fairclough's (1989, revised 2015) dialectical relational approach, the corpus linguistic tool of Antconc, chi-square test on R-Studio and normalised relative frequencies. Data analysis revealed that the different participants in the discourse characteristically used different modal resources to reflect their power on the one hand and resistance on the other and to capture the intensity of their views and feelings on the actions required for Nigeria to experience genuine social transformation. The study concludes that even though the discourse is largely ideational, modal resources are deployed for emphasising the urgency and seriousness of the issues in the ideational contents of the discourse.
\end{abstract}

\section{Keywords}

corpus linguistics, critical discourse analysis, modality, Nigeria, social transformation campaigns

\section{Introduction}

The agency of language in mediating and impacting serious issues in the society continues to manifest in human societies. Halliday and Matthiessen (2004) assert that people use language to organise their experience, and Halliday (1985) asserts that construing the experience of the inner and outer worlds is a major function of language, which he calls the ideational function of language. Resta (1998: 2) corroborates Halliday's thought by stating that language serves the purpose of social construction. Fairclough (2003: 8) also states that "texts 
have causal effects upon, and contribute to changes in people (beliefs, attitudes, etc.), actions, social relations and the material world". The above opinions indicate that the way language is used and perceived shapes the world and the individuals in it.

The subject of the materiality of language in engendering social transformation becomes an important one in human societies. In the Nigerian context, which the present study focuses on, attention has been paid recently to the role of language in social transformation. This new reality is not unconnected with the numerous societal ills in the nation which have assumed dangerous dimensions and have undermined the well-being of the nation and its people. There is thus an aggressive campaign for social transformation in the nation where language is deeply implicated to persuade Nigerians to eschew negative behavioural practices.

The discourse of social transformation can be said to be ubiquitous in Nigeria, emanating from both the government and the citizens. Even though the current government launched the campaign for social transformation in Nigeria on September 8, 2016, which it tagged Change Begins with Me, the citizens had through their civic engagement afforded by growing democratic and digital cultures popularised such campaigns through platforms such as Twitter, Facebook and other social networking sites. However, there is paucity of research on the subject from the linguistic perspective.

The present study therefore attempts a corpus-based critical discourse study of modality in the discourse in order to explore the attitudes of the discourse participants to the realities in the nation and the ways of changing the realities. Since according to Palmer (2001), modality is concerned with a speaker's attitude or opinion regarding the proposition in a clause, a study of the deployment of modal resources in social transformation campaigns in Nigeria can reveal the prominent attitudes and stances of the different categories of participants in the discourse. Through the comparison afforded by the stratification of the participants (state actors (SA) vs. non-state actors (NSA); (male vs. female) and their power disequilibrium, the corpus-assisted critical discourse analysis grounding of the work enables one unpack exertions of power and resistance in the discourse in order to reveal the altruism or otherwise of the contributions of the discourse participants. Therefore, the study seeks to provide answers to the following research questions:

i. Which modals are significantly used in the discourse of social transformation in Nigeria?

ii. What attitudinal and other interpersonal meanings are communicated through the use of the modals? 
iii. Are there any correlations between the modals used in the discourse and the sources of the texts?

\subsection{Perspectivising social transformation campaigns in Nigeria}

Social transformation campaigns are a significant feature of postindependence Nigeria due to perceived and obvious need for behavioural change among Nigerians at different levels since the nation attained independence in 1960. The discourse has received the attention of both government (military and civilian) and non-governmental organisations and individuals. Some of the social transformation campaigns introduced by the government of Nigeria over the years are Reconciliation, Reconstruction and Rehabilitation, War Against Indiscipline, Mass Mobilisation for Self-Reliance, Social Justice and Economic Recovery and National Orientation Agency (Nwankwo et al. 2012) and most recently, Change Begins with $\mathrm{Me}$. These various social transformation campaigns and programmes were necessitated by the prevailing negative conditions of various epochs in the history of the nation.

On the other hand, the non-governmental contributions to social transformation campaigns in Nigeria have emanated from the civil society, the press, trade unions through the mass media and most importantly, in the recent times, through civic engagement in the new media. However, it must be stated that until recently, non-governmental campaigns for social transformation in Nigeria have been hindered by the military system of government which held in Nigeria at different times from 1966 to 1999. But with the re-entrenchment of democracy in Nigeria in 1999 and the rapid penetration of digital life into the nation in the last decade, non-governmental or private contributions to social transformation campaign have been tolerated and impactful, as there are diverse means of turning the heat on erring government actors, agencies or individuals in the nation now. Opeibi (2016) remarks that this is a good development, as it has the capacity to shape not only government policies and actions but also the behavioural patterns of the citizens in general.

Scholars (e.g. Agang 2014, Ajiwe et al. 2015, Burgess 2013, Saale 2014, Raphael 2014) have studied the national-cum-social transformation discourse in Nigeria from religious and sociological perspectives. From the religious angle, scholars have examined the place of prayer and the church in Nigeria's national transformation drive (Akanbi \& Beyers 2017, Saale 2014), the potentials of character building through religious values (Raphael 2014) and the role of charismatic Christian preaching (Burgess 2013). From the sociological perspective, the agency of the home video in facilitating social transformation in Nigeria has also been studied (Ajiwe et al. 2015). 
Linguistic studies on national transformation advocacy in Nigeria have focused on the place of language in social transformation (Adedimeji 2005, Fakuade 2015), stylistic features of conflict resolution advocacy texts (Oyebamiji 2013), transformation of political cultures in Nigeria (Opeibi 2015, 2016), and discursive strategies of social transformation advocacy in Nigeria (Ademilokun 2019).

Adedimeji (2005) explores the place of language in societal transformation in Nigeria. The paper argues that "language performs four functions: to form, to inform, to reform and to transform man and his society" (Adedimeji 2005: 1). Using the systemic functional linguistic grammatical categories, Adedimeji (ibid.) posits that "the ultimate solution to the ethnic, religious, political conflicts estranging Nigeria lies in the application of language functions to national development".

Fakuade (2015) also argues for the role of language in national transformation focusing on the place of the English language in the reformation of the Nigerian nation. He states that since the primary agents of transformation in Nigeria (education, information and technology and the media) are mediated through the English language, the language plays an important role in the rejuvenation of the Nigerian society.

Oyebamiji (2013) carries out a multimodal-stylistic analysis of conflict resolution advocacy campaigns in Nigeria, focusing on data relating to oilpipe vandalism, terrorism and child-trafficking. The work concludes that verbal and non-verbal signifiers are copiously used in an interactive manner for the production of meaning in the discourse.

Opeibi (2015) focuses on the use of new technologies for the transformation of the Nigerian political culture and the creation of a new public space in the country. The study shows that the emancipatory use of language in the new media is for the purpose of bridging the communication gaps between the political leaders and the citizens. Such borderless interaction afforded by language use in the new media enhances the ability of the citizens to positively impact the policies and actions of their political leaders.

Ademilokun (2019) examines the discursive strategies used in negotiating the social transformation agenda in Nigeria. The study reports that the discourse participants deploy framing, legitimation, rhetorical questions, linguistic nativism, metaphorisation of social transformation acts and accentuation of the repercussion of negative actions. The study concludes that the discourse still reflects the class configuration in the Nigerian society.

While the above reviewed studies have focused on aspects of social transformation discourse in Nigeria from diverse linguistic perspectives, one 
realises that there is a neglect of the use of modality in the discourse in the literature. Since modals have been widely acknowledged to index attitudes and commitment levels to propositions, we believe a focus on modal resources in the discourse of social transformation in Nigeria will reveal important nuances of meaning regarding Nigerians' prosecution of the social transformation campaigns.

\section{Modality: Some theoretical background}

Modality is an aspect of Systemic Functional Linguistics drawn upon in critical discourse analysis. Halliday (1994:75) asserts that modality is the "speaker's judgment of the probabilities or the obligations involved in what he is saying". Verschueren (1999, as quoted in Fairclough 2003:165) also remarks that modality is concerned with the "many ways in which attitudes can be expressed towards the pure reference and predication content of an utterance, signalling factuality, degrees of certainty or doubt, vagueness, possibility, necessity, and even permission and obligation".

Nuyts (2006) recognises three kinds of modality: deontic, epistemic and dynamic. Downing and Locke (1992: 382) remark that in deontic modality, the text producer "intervenes in the speech event by laying obligations or permissions". Therefore, deontic modals are used to influence actions and situations based on the morality of the text producer which could be informed by societal or personal dispositions (Huddleston \& Pullum 2002: 54). Greenbaum (1996: 260) captures this by stating that "deontic meanings refer to some kind of human control over the situation, such as permission or obligation". However, most modals are generally polysemous, as some words that are deontic modal auxiliaries can also be epistemic modal auxiliaries. However, of the nine central modals, deontic meanings can be realised through must and should.

Greenbaum (1996: 260) remarks that "epistemic meanings refer to some kind of judgment of the truth-value of the proposition, such as its possibility or necessity". Such modality "marks the degree/and or source of a speaker's commitment to the embedded proposition" (Papafragou 2006: 1689). Epistemic modality can be realised through modal verbs such as may, might, will, should, can, could and must.

Dynamic modality is the third contestable category of modality in English grammar. According to Nuyts (2006: 7), in the traditional sense, it is used to refer to "ascription of capacity/ability to the subject participant in the clause". Palmer (2001) remarks that only the modals can and will can communicate dynamic meanings. 
The modals, however, have different degrees of certainty, i.e. modal force. Winiharti (2012) remarks that the intensity of deontic modals reflects in their respective functions (obligations and permission). According to Winiharti (ibid.), with respect to obligation, must and should are usable in formal contexts but while must reflects the highest level of intensity, should is reflective of the lowest level of intensity. Also concerning permission, the author remarks that can is marked by the highest level of intensity followed by could, may and might in that order.

On the other hand, with regard to epistemic modals, the strength of the modals according to Winiharti (2012: 536) can be represented as follows:

will - highest intensity

should - high intensity

may - low intensity

could/might - lowest intensity

Jordan (1999) also remarks that regarding the central modals which the present study focuses on, while must, shall, will and can are generally acknowledged to express a high degree of certainty with respect to their functions, may, should and would express median/moderate values of certainty and might and could express a very low level of certainty.

Greenbaum (1996: 260) describes the uses of modals in the English language. He states that will and would are used for making future predictions, present predictions, habitual predictions and for expressing volition. According to Greenbaum (ibid.: 262), shall and should are also used for making predictions and expressing volition with first person subjects while must is used for expressing certainty and obligation. The modals can and could are also used for expressing ability, seeking or granting permission and expressing possibility (see Greenbaum 1996: 260-261, Biber et al. 1999). Finally, the remaining two central modals, may and might are used for expressing permission, possibility and ability (Biber et al. 1999, Greenbaum 1996).

Studies abound on modality in academic discourses (e.g. Vázquez Orta 2010, Kuchler 2015, Olaniyan \& Adeniji 2015, Ngula 2017) and political discourses (e.g. Boicu 2007, Lillian 2008, Nartey \& Yamkson 2014, Vukovic 2014). Studies on modality in political discourse have focused on its use for positive self-representation and negative other-representation in manifestos (see Nartey \& Yamkson 2014) and parliamentary discourse (see Vukovic 2014). Scholars have also focused on modality in media discourse, examining the relationship between modality and point of view (see Iwamoto 2007), the creation of attitudes in editorials (see Bonyadi 2012, Lihua 2009) and the new media (Rui \& Jingxia 2018). 
Even though the literature highlights the centrality of modality to academic, political and media discourses, it does not indicate much about the character of modality in the new media, which is part of the present research, hence some justification for the present research. In addition, none of the previous studies has focused on modality in social transformation campaigns, thus making the present study imperative.

\section{Methodology}

Data for the study comprises advocacy on social transformation in Nigeria from state actors and non-state actors. State actors are considered as government functionaries from the President down to government parastatals (National Orientation Agency, Ministry of Information, Nigeria Police, etc.). The non-state actors are the citizens and non-governmental organisations who seek to influence the actions of the government through their civic engagement.

The target population are speeches, interviews, radio programmes, television advertisements, jingles, online discourses, banners, flyers and posters conveying messages of social transformation that border on democratic impropriety, restoration of values, insurgency/security and gender inequality. The focus on the four issues is borne out of their topicality in Nigeria.

Small specialised corpora of 25,660 words are used for the study due to peculiar challenges of obtaining large data from relevant Nigerian government agencies and media houses which largely have poor record-keeping culture. The stratified sampling method was employed to build the corpora because "stratified samples are almost always more representative than non-stratified samples" (Biber 1993: 245). Therefore, we tried to represent the groups of the population by purposively obtaining data from speeches, jingles, radio commentaries, printed materials, online texts and interviews. Data collected was produced between March 2013 and March 2018. The five-year span was informed by the numerous challenges in Nigeria (insurgency, Fulani killings, financial misappropriation and democratic impropriety) in the time frame which led to the intensification of the campaigns for social transformation in the nation.

The corpus creation was, however, influenced by the nature of communication peculiar to state actors and non-state actors with respect to the social transformation agenda of Nigeria. For instance, while non-state actors often use tweets and Facebook posts, state actors often use jingles and speeches. Also, there is difference in the number of text samples from tweets and jingles as opposed to others due to the fact that the contributions in the various text sources vary in word counts.

More importantly, data for the qualitative aspects of the analysis was purposively obtained from the corpus to serve the purpose of analysis at every 
analytical level, paying attention to the relevance of the fragments of the discourse to the analytical level concerned. On the other hand, where corpus linguistic/statistical tools of Antconc and R-studio are employed for quantitative analysis in the study, the analysis is based on the entire corpus. This implies that the entire data was uploaded to the concordance analyser in order to get a full representation of the use of modal resources in the discourse.

In order to account for gender differences in the contributions of the discourse participants, we try to segment the data based on gender, where possible. For instance, while the discourse of state actors is characterised by data from governmental bodies that are not gendered and also shows a domination of male voice owing to the gender imbalance in the occupation of political positions in Nigeria, we were able to map contributions of female non-state actors to Nigeria's discourse of social change through sentiment analysis, by paying attention to the topics of the discussions and verifying the twitter handles that appear to be those of females. Some of the contributions of females were also obtained from speeches and interviews on television sets, which clearly reveal their identities.

In the analysis of the data, quantitative and qualitative readings of the texts were done in order to allow for objective interpretation of data devoid of biases of the analyst. We focused on concordance analysis of the modals, paying attention to key words in context and collocation using Antconc. In order to investigate the associations between the modals and the text producers and the significance of the usages of modals in the discourse, chi-square test was carried out using R-studio. Since the corpora (SA and NSA) and the sub-corpora (MNSA \& FNSA) do not have the same amount of text tokens, we calculated the normalised relative frequencies of the modals in the corpora. This afforded us the opportunity to compare the usages of the modals by the discourse participants and the implications of their differences. The calculation was done per 10,000 words.

Below are the corpora and the sub-corpora for the study.

\begin{tabular}{|l|c|c|}
\hline Text Type & Number & Text Tokens \\
\hline Speech & 8 & 6,079 \\
\hline Radio Commentaries & 8 & 2,855 \\
\hline Jingles & 15 & 1,829 \\
\hline Printed Materials & 8 & 2,132 \\
\hline Total & & 12,895 \\
\hline
\end{tabular}

Table 1: State Actor (SA) Specialised Corpus 


\begin{tabular}{|l|c|c|}
\hline Text Type & Number & Text Tokens \\
\hline Speeches & 5 & 1,082 \\
\hline Interviews & 5 & 7,552 \\
\hline Jingles & 5 & 455 \\
\hline Newspaper Comments & 45 & 1,629 \\
\hline Tweets and Facebook Posts & 45 & 2,047 \\
\hline Total & & 12,765 \\
\hline
\end{tabular}

Table 2: Non-state Actor (NSA) Specialised Corpus

\begin{tabular}{|l|c|c|}
\hline Text Type & Number & Word Tokens \\
\hline Tweets and Facebook Posts & 39 & 1,734 \\
\hline Interview & 4 & 4,513 \\
\hline Newspaper comments & 57 & 1,629 \\
\hline Total & & 7,876 \\
\hline
\end{tabular}

Table 3: Male Non-State Actor (MNSA) Sub-corpus

\begin{tabular}{|l|c|c|}
\hline Text Type & Number & Word Tokens \\
\hline Speeches & 4 & 1,082 \\
\hline Interview & 1 & 3,039 \\
\hline Tweets & 6 & 313 \\
\hline Total & & 4,434 \\
\hline
\end{tabular}

Table 4: Female Non-state Actor (FNSA) Sub-corpus

\section{Theoretical framework}

This study is grounded in corpus-assisted critical discourse analysis (CDA). According to Baker et al. (2008: 274), corpus-assisted critical discourse analysis involves a blend of principles of corpus linguistics and critical discourse analysis "without each being subservient to the other but that each [...] contributes equally and distinctly to the methodological synergy". While the question of 
equal representation of the principles of corpus linguistics and critical discourse analysis in an analysis is relative, the idea underlying corpus-assisted critical discourse analysis is that precepts of both methods should reflect in the analysis for the interpretation of the inherent meanings in the text. Partington (2003) notes that notable advantages of combining critical discourse analysis and corpus linguistics are that corpus techniques can help highlight examples of features already noted in a corpus, patterns that were previously unknown, and in the process help to support, refute or revise a researcher's intuition regarding such linguistic features.

Corpus-assisted critical discourse analysis follows the precepts of corpusassisted discourse analysis with the addition of a critical component to the analysis. Therefore, it is characterised by concepts such as keyword in context, collocation, keyness, frequencies, among many others. Such corpus-based principles are favoured in the kind of analysis because they reduce the bias of the analyst by providing quantitative evidences for the interpretations made from texts.

For the purpose of the present paper, the corpus-based precepts employed in the analysis of the data are concordance and key word in context, collocation and chi-square test for statistical significance. Through the above-listed aspects of corpus linguistic analysis, some verifiable interpretation of the usages of modals in the discourse of social transformation in Nigeria is achieved. Furthermore, the statistical test of chi-square reveals the authenticity or otherwise of the meanings expressed by the modals by showing the associations between the modals and their producers in the discourse.

The critical discourse analysis component of the present study relies on Fairclough's (2015) dialectical-relational approach to critical discourse analysis given its affordances for social analysis which ties with the nature of the discourse being studied. Data analysis from the perspective of dialectical relational approach spans the three stages of analysis in CDA identified as description, interpretation and explanation (Fairclough 2015).

\section{Findings and discussion}

In this section, we present the quantitative and qualitative findings from the study. The analysis starts from the quantitative to the qualitative while highlighting the interactions of the two. 


\subsection{Quantitative analysis of modals in the discourse}

In order to test the correlations of modal resources and the text sources in the discourse of social transformation in Nigeria, we carry out a chi-square test on the use of modals. For a visual illustration of the use of modals in the discourse generally, we present the association plot for modals in the discourse and then discuss the results:

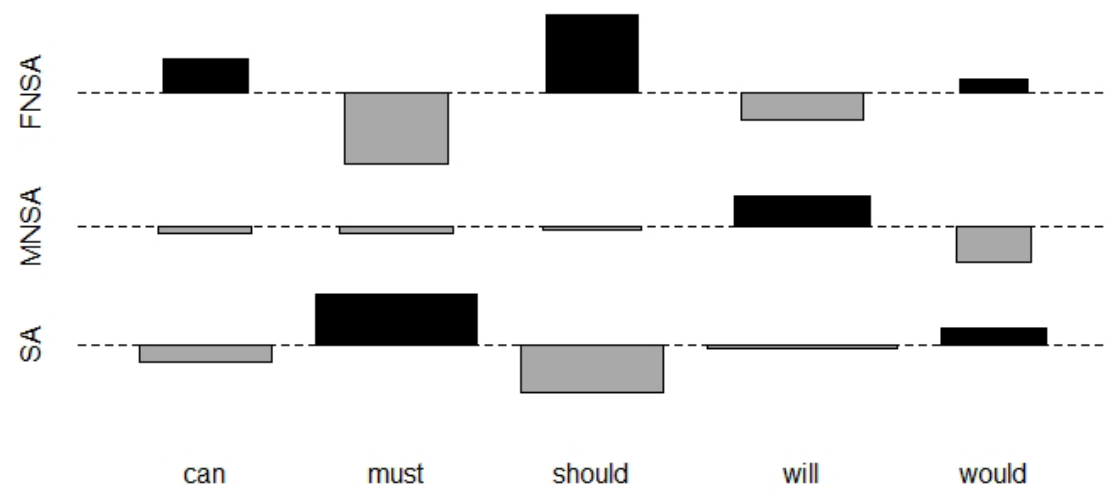

Figure 1: Association Plot for Chi-Square Test on Modals

The chi-square test shows that the use of modals in the discourse of social transformation in Nigeria is highly significant as the $0.01 \mathrm{p}$-value from the Pearson test confirms the significance of the use of the modals because it is much lower than the 0.05 threshold for significance in chi-square tests. This affirms that there is correlation between the text sources and the modal choices made in the discourse (see Gries 2013: 189). The implication is thus that to a large extent, the modal resources in the discourse are motivated and strategic. However, the Cramer's V is low (0.144), showing that even though there is association between the text sources in the discourse and the modal choices made, the effect is not particularly strong (ibid.). The implication of this is that there may be other factors that contributed to the modal choices made in the discourse.

As can be seen from Figure 1, the modals must, will and should make the greatest contribution to the chi-squared value of the modals, as the figure shows that the biggest black rectangles are found in the columns for the three modals. Following these three are can and would. This is because, as Gries (2013: 188) observes, "the black rectangles above the dashed lines indicate observed frequencies exceeding expected frequencies; grey rectangles below the dashed 
lines indicate observed frequencies smaller than expected frequencies; the heights of the boxes are proportional to the above Pearson residuals and the widths are proportional to the square roots of the expected frequencies". This is not surprising as the three columns for the three modals have a chi-square value of 16.212 of the 19.144 total chi-square value of the modals. However, while the use of must has the greatest positive sign of significance in the contributions of state actors, the use of should has the greatest positive sign for significance in the contributions of female non-state actors and the use of will has the greatest positive sign for significance in the contributions of male non-state actors. While both must and should are deontic modals, as stated earlier, the former shows the highest level of intensity with regard to its function (obligation or permission) while the latter shows the lowest level of intensity for the same functions (Winiharti 2012). Against this background, one can say that the state actors prefer must for deontic purposes, in reflection of their authorial status, which enables them to assert to the citizens without having any fear of being considered offensive or immodest.

The penchant of female non-state actors for the use of should can however be seen as an expression of their conscious desire for a change in the status quo in the Nigerian nation as they emphasise the need for certain changes in the nation through the modal. With regard to male non-state actors, one can perceive their preference for will in the discourse as a reflection of the strong conviction of men in advocating issues of public concern in the Nigerian social and political spaces, owing to their several years of emancipation in the society. Since will shows a greater degree of certainty and commitment than would, one can say that the non-state actors are more aggressive about the issues that they engage with.

\subsection{Deontic modality in Nigeria's social transformation campaigns}

Nigeria's social transformation discourse features a great deal of deontic modality. As stated in Section 2.2, deontic modals are mainly used to express obligations and permission rooted in the idea of moral desirability, such as must, should, etc. Below, we present examples of the use of deontic modals in the discourse:

\section{Excerpt 1}

NSA Tweet (Twitter Nigeria, January 23, 2018)

Today it saddens my heart that this government has gotten to the point where they intimidate and threaten the lives of its citizens instead of addressing the concerns of the killings and abduction of its citizens @obyezeks @BBOG_Nigeria @emekakickoff...We must rise up now. 


\section{Excerpt 2}

NSA Interview (TVC, January 1, 2017)

My only advice to government is that they must fight this corruption with a commitment that shows openness, transparency and accountability... Therefore, those fighting corruption or those prosecuting corrupt cases must not engage in corruption. It is bad to rob Peter to pay Paul.

Excerpts 1 and 2 are typical examples of how deontic modality is used in the discourse to influence the actions of the audience by presenting certain actions and ideas as expediently desirable. In Excerpt 1 for instance, there is the use of must by the text producer to call all Nigerians to action against the government, which is presented as intimidating the citizens for agitating for their rights. Having presented an unfortunate state of the nation, the text producer attempts not only to instruct but also compel the audience, i.e. Nigerians, to fight the government against their perceived oppression. The collocate of the modal must in the excerpt rise also conveys a meaning that is related in force to the modal as it is a metaphorical verbal expression which is meant to instigate the citizens of Nigeria to carry out a protest against the government over their clampdown on activists agitating for more government action to ensure the release of the girls abducted by Boko haram insurgents in Northeastern Nigeria. This shows the use of deontic modality in the corpus of non-state actors to resist the power of the government while asserting power for every Nigerian, which is grounded in the resistance ideology in the discourse where text producers mobilise the citizenry for collective action considered beneficial to the social transformation agenda of Nigerians for their country.

Excerpt 2 also reflects the use of deontic modality by non-state actors for the expression of their resistance ideology against government inadequacies or excesses inimical to the positive transformation of Nigeria, even though in a mild way. Here, both instances of must in the short text are meant to influence the government of Nigeria by requiring certain actions of them in order to improve the situation of Nigeria. This fact is reflected in the collocates of the modal in the two instances fight and not engage in, which are both transitive verbs attracting the object corruption. Even though such deployment of deontic modality does not explicitly pursue resistance, it shows the growing trend of criticism of the government by Nigerians afforded by the democratic experience in the nation.

However, although the text producer is not explicitly showing resistance to the government, the meaning can be read that the text producer is constructing a negative identity for the government of Nigeria as people who have certain habits that foster corruption and other causes of national problem. Therefore, the government is being asked to break away from such practices through the use of 
the modal verb must. Therefore, it can be said that there is a subtle expression of counter-hegemonic view of the source of social problems in Nigeria, which challenges the idea that change proceeds from the Nigerian people central to the Change Begins with Me campaign of the Nigerian government. Below are more examples of the deployment of deontic modality in the discourse:

\section{Excerpt 3}

SA Speech (September 8, 2016)

We must resist the temptation to fall back to the same partisanship, pettiness and immaturity that have poisoned our country for long.

\section{Excerpt 4}

SA Speech (Vanguard Newspaper, January 10, 2018)

You must be determined to work hard, you must ensure to be a person of integrity.... and you must not see yourselves as young people of southwest alone...You must make contacts across the country, you must build bridges across the country; you must see yourself first and foremost as a Nigerian citizen.

Excerpts 3 and 4 above depict the use of deontic modality by state actors in the discourse of social transformation in Nigeria to influence the citizens to behave in certain ways that they consider would be beneficial to the people and the nation. The excerpts are typical of the expression of deontic meanings by state actors in the sense that the texts are produced by the President and the Vice President of Nigeria respectively. The deontic modal must and its verbal collocate resist in Excerpt 3 are used by the President to charge Nigerians in general to change their behaviour and disallow themselves from acting contrary to appropriate values in order for the conditions of Nigeria to change positively. The use of must in Excerpt 4 shows the typical way that a powerful or older person speaks to people of lower status or age. The modal verb is used five times in the short text by the text producer in admonishing the youth to accept the views of the text producer which he asserts are productive for the youth. Such usage of modals shows how power is subtly coded in the use of deontic modals by language users. The collocates of the modal in the excerpt also show two different kinds of meaning which the text producer intends to pass across. While the transitive verbal collocates not see and see and their objects, yourselves, are used to emphasise how the text producer wishes the addressees to perceive themselves, the collocates of the remaining four occurrences of the modal (be determined, ensure, make, build) highlight certain actions that the speaker considers essential for social change in Nigeria especially from the perspective of the youth that are being addressed. 
As can be seen from the excerpts, both categories of participants in the discourse tend to want the public to accept their views, and this reflects the growing fluidity of power in the society. It is significant that must is the most prominent linguistic item used for the realisation of deontic modality in the discourse. While the modal has a normalised relative frequency of 42.0 in the corpus, should, which is the other deontic modal significantly used in the corpus has a normalised relative frequency of 32.3. Even though the margin of the difference is not wide, must still represents the most used deontic modal in the discourse.

As revealed by the black rectangle in the column for the modal in Figure 1 , the deontic modal must is the most favoured modal by state actors. The association plot shows that its use by state actors outweighs that of non-state actors as the black rectangle in the column shows that it is favoured while the grey colour in the columns for male and female non-state actors shows that it is disfavoured in the contributions of the non-state actors. While the modal with 68 occurrences has a normalised relative frequency of 52.7 in the corpus of state actors, its 40 occurrences in the corpus of non-state actors translates to a normalised relative frequency of 31.3. This shows that even though non-state actors also boldly use such deontic modal in the discourse, state actors tend to be more assertive because they are mindful of their typical role of providing the roadmap to the people for their survival.

The deontic modal must occurs in the corpus of female non-state actors 13 times with a normalised relative frequency of 29.3 while occurring in that of males 27 times with a normalised relative frequency of 34.3 , showing that there is no significant difference in the use of the modal by both genders in the discourse. This indicates that both genders are conscious of the need for certain actions to be taken in Nigeria in view of the fact that they are both affected by the negative realities in the nation. Therefore, through their contribution to the discourse of social change in Nigeria, Nigerian women can be seen to be justifying their agitation for more involvement in governance by showing that they are aware of the realities in the society and are lending their voices to important issues of national transformation in a way that portrays them as being passionate for a socially transformed Nigeria. Thus, even though the proposal for inclusion of allocation of 35 percent of appointive and elective positions to women in the Nigerian constitution failed in the Nigerian Senate in July 2017 (Vanguard Newspaper, 18 August, 2017), this result shows how intense the feeling was among women and their demonstration of the capacity to utilise such privilege accordingly. 
Below, we attempt a concordance analysis of the modal must in the discourse in order to highlight its linguistic contexts and the social concepts they point to:

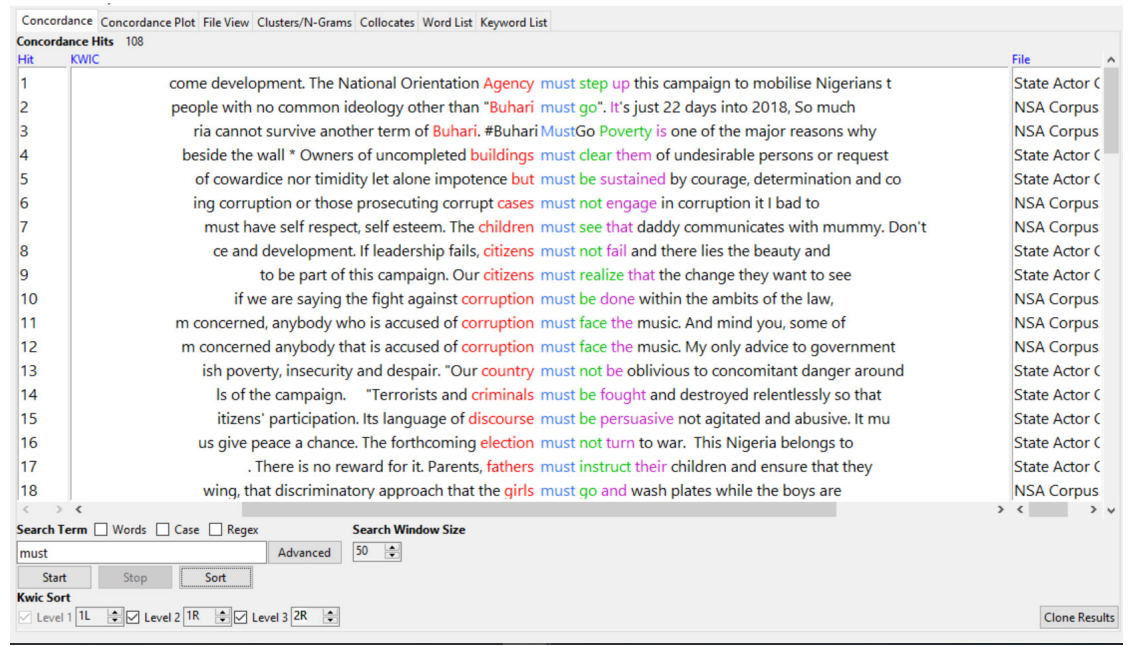

Figure 2: Keyword in Context (KWIC) for must

The screenshot above shows the contexts of the different instances of the modal must in the discourse. The figure shows certain prominent nominal lexemes representing concepts or actors that are expected to behave in certain ways in order for Nigeria to be positively transformed. In particular, the lexemes children, citizens and corruption refer to some of the people and things that must act in certain ways or must be dealt with in certain ways for Nigeria to be positively transformed.

The concordance and key word in context show that the verbal groups be done and keep to procedures represent the most frequent verbal collocates of the modal, indicating certain positive actions that are considered important for the transformation of Nigeria. Many other verbal expressions such as face the music, have a change of, restructure and be stopped reflect certain actions with transformative effects in the Nigerian society.

The second significantly used deontic modal in the discourse is should. Below are instances of the use of should in the discourse: 


\section{Excerpt 5 \\ SA Commentary (Radio Nigeria)}

Religious leaders should also focus more on core values that will dissuade people from negative behaviour.

\section{Excerpt 6 \\ Tweet (Twitter Nigeria)}

Female genital mutilation is barbaric and should be banned from Ebonyi.

Excerpt 5 shows that should is another modal that is used to instruct and influence people to accept certain views or behave in certain ways in the discourse, even though as Figure 1 shows, it is favoured most by female non-state actors. In the sentence in which it is used, the text producer sounds lamentative about the concentration of religious leaders' preaching on issues other than the inculcation of appropriate morals in Nigerians and offers to them the idea of focusing on morals for the betterment of Nigeria using the modal should to justify his suggestion.

Excerpt 6 shows the use of the modal should for evidencing humility by persons invested with power, as the person who produces the text is a monarch who ordinarily should sound assertive but rather sounds subtle in expressing his conviction. The text producer is convinced that female genital mutilation has to be expunged from the Nigerian society as reflected in his description of the practice as barbaric. Therefore, given his hatred and intolerance for the practice and his position as a king, one would have expected him to use the most assertive deontic form, must. Rather, he chooses to use the subtle form of deontic modality in should.

It is interesting that while the modal has the normalised relative frequency of 38.4 in the corpus of non-state actors, it has 26.4 in the corpus of state actors. This shows that non-state actors have the tendency to slightly deploy the modal more than state actors in the corpora. This is confirmed in the association plot in Figure 1, where the use of the modal is marked favoured in the contributions of females because the modal has a normalised relative frequency of 63.1 in the sub-corpus of females as opposed to 26.7 in that of males.

A reasonable number of the collocates of should in the discourse are nominal, referring to Nigerians as actors in different capacities who are expected to act in certain ways for the nation to be regenerated. It is interesting that the nominal that occurs most frequently with the modal is the inclusive pronoun we, showing that there is the foregrounding of roles and actions of the Nigerian collective for the real transformation of the Nigerian society. In a manner similar to the collocates for must, there are also certain positive collocates of the modal, indexing positive actions to be taken for the rejuvenation of the nation. 


\subsection{Epistemic modality in Nigeria's social transformation campaigns}

Epistemic modality as discussed in section 2.2 is the kind of modality that reflects the commitment of a text producer to the proposition in his or her expression. Examples of epistemic modals are will, would and may in which case will expresses greater certainty than the latter two (Jordan 1999). The participants in the discourse deploy epistemic modality significantly to evaluate the truth of their propositions in the discourse and to show their commitment to the social transformation campaign. Below are instances of epistemic modality in the discourse:

\section{Excerpt 7}

\section{SA Printed Text (National Orientation Agency)}

When you are angry, you need to wait until you cool off before you act. Quick responses from unprepared hearts only complicate the situation and in the end, you may lose.

\section{Excerpt 8}

\section{SA Printed Material (National Orientation Agency)}

Dishonesty will rob you of your reputation, respect and your influence.

Excerpts 7 and 8 above illustrate how epistemic modals are used by text producers to judge the truth of the propositions in their texts. In Excerpt 7, the modal verb may is used to evaluate the text producer's view of the consequence of responding spontaneously in a state of anger. The use of the moderate modal, however, presents the text producer as a cautious person who does not want to make a categorical statement as he could have asserted that one would lose when reacting spontaneously in a state of anger. Since Fairclough (2003) states that modality is useful for texturing identities, the deployment of the evaluative modal thus serves in revealing an aspect of the personal identity of the text producer as cautious, which in fact synchronises with the message of caution that the text itself conveys. The epistemic modal used to convey the meaning in the text is persuasive like in Milkovich and Sitarica (2017: 79) where "politicians use epistemic modality in order to persuade the hearers or the voters that what they do is right and reasonable even though there often is no firm evidence which would support their claims".

Excerpt 8 is characterised by a greater level of evaluation or commitment to the truth of the proposition in the sentence. Here, the modal verb will marked by the highest level of certainty is used to emphasise the negative effect of dishonesty in a way that presents dishonesty to Nigerians, especially the young as a very bad character trait that they should avoid. Such high level of evaluation 
is rampant in the discourse in view of the fact that the discourse participants often show their attitudes and feelings towards the negative realities in Nigeria and suggest new ways for Nigeria to combat the many negative realities. Further examples of epistemic modality in the discourse can be found below:

\title{
Excerpt 9
}

NSA Tweet (Twitter Nigeria, January 23, 2018)

Let us be clear, a fire brigade approach for a third political force in Nigeria may not fail in its aim to ascend the throne. However, it will implode like the APC for a simple reason...

\begin{abstract}
Excerpt 10
NSA Interview (Sunrise, Channels Television, December 13, 2014)

Mothers still have that critical role, they still have that main role in moulding the boy, so that when the boy grows up, when the boy reaches that pedestal, one day he becomes husband, he would have learnt a lot of home training from what the mother has said and the father too would have helped a lot by not beating the mother.
\end{abstract}

The texts above show how epistemic modals are used by non-state actors to gauge their commitment to the truth of the propositions in their utterances. In Excerpt 9, the modals may and will are used by the text producer to show his attitude towards the issue of forming a new political movement in Nigeria as suggested by President Obasanjo. The stance expressed is no doubt negative as shown by the use of the two modals. While the assessment of the third political force is not fully negative as the text producer uses a tentative modal verb to reflect his view about the likely success of such a political formation, his attitude towards the ultimate future of such a political formation is no doubt negative as he uses a strong modal form will to evaluate the outcome of such a formation in a negative way. This high level of evaluation is not uncommon in the discourse due to the importance of the issues discussed and the passion with which the discourse participants broach such issues.

Excerpt 10 also serves in conveying the personal assessment of the text producer regarding the proposition that mothers have a critical role to play in moulding a boy to grow up to appreciate his wife and the impact of that on the boy when he eventually becomes a man. The use of the moderate modal would conveys the belief of the text producer in a mild way rather than in an assertive way, showing that even though the text producer believes in the plausibility of his or her proposition, he or she is mindful that other factors may also come into play regarding the issue at hand. 
The modal will is the most dominant epistemic modal in the corpora with 151 occurrences and a normalised frequency of 58.8 compared to would (45) with a normalised frequency of 17.5. While the normalised frequency for the use of the modal by state actors reveals 60.5 , it has a relative frequency of 57.2 in the corpus of non-state actors. This shows that there is a balanced use of the modal by both categories of text producers, showing that both of them are committed to their propositions regarding the subjects around social transformation. Even though there are few instances of hedging, hedging cannot be said to be a typical feature of the discourse as the discourse participants generally pointedly express their feelings regarding the situation of Nigeria and Nigerians and the actions to take to confront the challenges facing the nation.

However, the association plot in Figure 1 shows that the use of will is statistically favoured in the sub-corpus of male non-state actors, even though the modal has a relative frequency of 57.1 in the sub-corpus of male non-state actors and 63.1 in that of female non-state actors. While the revelation from Figure 1 may be said to reflect the assertive nature of men in Nigeria, the slightly higher normalised frequency of the modal in the sub-corpus of females shows that there is no doubt increasing active involvement and commitment of women to the propositions they make regarding social transformation in Nigeria. Therefore, the agitation of women for more inclusion in governance in Nigeria cannot be said to be too ambitious or misplaced in view of the significant and affirmative contributions of women to the discourse on social transformation in Nigeria. Below, we present a key word in context for will in the discourse:

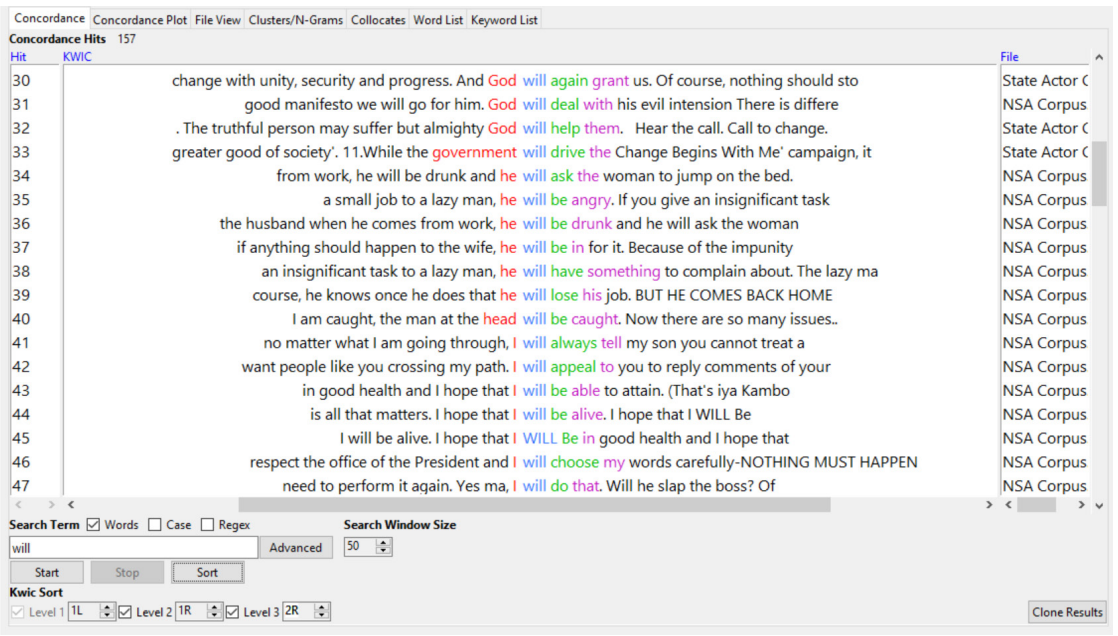

Figure 3: Key word in Context (KWIC) for will 
The KWIC for the modal will reveals the co-occurrence of words such as children, $I$ and $h e$, with the modal. Many of the nominal collocates of the lexeme are used to highlight the major concerns in Nigeria which the text producers address in their propositions. For instance, corruption and dishonesty are vices prevalent in the Nigerian society which the text producers seek to expunge from the body polity in the nation through the concept captured in the nominal expression campaign. The text producers also show assertion through the negative and positive collocates of the modal (positive: Be well, Help restore, etc.; negative: kill Nigeria, rob you, etc.). While the positive collocates emphasise the rejuvenation that will happen to Nigeria if certain actions are carried out, the negative collocates emphasise the perspectives of the text producers on what would befall Nigeria and Nigerians if the negative realities persist.

\section{Conclusion}

The study has examined the modal resources deployed in the discourse of social transformation in Nigeria. The study draws on corpus-assisted critical discourse analysis to demonstrate how the participants in the discourse use the modal resources to mark their commitment to the various issues that they engage in relation to the social transformation drive of the Nigerian nation. The study also shows how the various categories of participants in the discourse tacitly assert and resist power and convey their ideologies within the purview of the Nigerian socio-cultural milieu.

The quantitative analysis afforded by chi-square confirms that there is indeed association between the modal resources in the discourse and their producers, thus indicating that the modals were intended to communicate certain motivated meanings by the producers. The study reveals that modals in the discourse of social transformation in Nigeria communicate important interpersonal meanings, most especially reflecting the commitment of the text producers towards their text outputs. The analysis reveals that the passion of the text producers for a transformed Nigeria impacts on their modal choices, leading to the prevalent use of the deontic modal must by both state actors and non-state actors. However, the study further elucidates that while the usages of the deontic modal must by state and non-state actors reflect power asymmetry between both categories of participants in the discourse, its relatively balanced use by male and female non-state actors is indexical of the growing female assertion and participation in socio-political issues in the Nigerian nation.

The study also shows that the participants in the discourse further mark their passion and enthusiasm for the nation through their high level of commitment to the locutions they make about the Nigerian nation through their balanced use 
of epistemic modals, particularly the modal will. It is further significant that even though men are more convincing in their commitment to the ideas of social transformation in the discourse as women deploy more of should than will, the level of their use of the modal will is striking enough to justify their popular advocacy for more inclusion in public affairs in the Nigerian context. The study concludes that even though modals are generally indexical of the attitudes of the text producers to the ideas expressed in their texts, they also bear power and reflect the broad ideological configuration of the Nigerian society.

\section{Acknowledgements}

I thank the Alexander von Humboldt Foundation for awarding the Georg Forster Fellowship, which afforded me the opportunity to conduct the research leading to this article. I profoundly appreciate the critical comments and guidance of my host, Prof. Dr. Josef Schmied and his research group who helped to refine my thoughts while working on the draft. I am also grateful to the anonymous reviewers for their helpful comments.

\section{References}

Adedimeji, M. (2005) 'The unifying role of English in a multilingual nation: The case of Nigeria.' In: Ndimele, O. (ed.) Language and Culture in Nigeria. Abia: National Institute for Nigerian Languages. 67-74.

Ademilokun, M. (2019) 'Discursive strategies in select mediatised social transformation advocacy in Nigeria.' Discourse, Context and Media 28, 44-51.

Ajiwe, U., Okwuosa, S. and Chukwu-Okoronkwo, S. (2015) 'Nigerian videofilms as effective tool for social transformation: A critical appraisal of Fola Toro.' American Journal of Social Science Research 1(2), 57-62.

Agang, S. (2014) 'Nigerian Pentecostal/charismatic theology of public engagement.' Erudite Journal of Social Science Research 2(1), 1-14.

Akanbi, S. and Beyers, J. (2017) 'The church as a catalyst for transformation in the society.' Theological Studies 73(4), 1-8.

Baker, P., Gabrielatos, C., Khosravinik, M., Krzyzanowski, M., McEnery, T. and Wodak, R. (2008) 'A useful methodological synergy? Combining critical discourse analysis and corpus linguistics to examine discourses of refugees and asylum seekers in the UK press.' Discourse \& Society 19(3), 273-306.

Biber, D. (1993) 'Representativeness in corpus design.' Literary and Linguistic Computing 8(4), 243-257.

Biber, D., Johansson,S., Leech, G., Conrad, S. and Finegan, E. (1999) Longman Grammar of Written and Spoken English. Edinburgh: Pearson Education Limited.

Boicu, R. (2007) 'Modal verbs and politeness strategies in political discourse.' Munich Personal RePEc Archive, 1-17.

Bonyadi, A. (2012) 'Linguistic manifestations of modality in newspaper editorials.' International Journal of Linguistics 3(1), 1-13.

Burgess, R. (2013) 'Nigerian Pentecostalism and civic engagement: Mission in the midst of poverty and violence.' TCNN Research Bulletin 58, 9-42. 
Downing, A. and Locke, P. (1992) A University Course in English Grammar. Hemel Hempstead: Phonix ELT.

Fakuade, G. (2015) Language and national transformation: The case of English in Nigeria. Paper Presented at the $31^{\text {st }}$ Annual Conference of the Nigeria English Studies Association (NESA) on English Language, Literature and National Transformation at The Federal University Lokoja, Kogi State, Nigeria, October 26-29.

Fairclough, N. (1989) Language and Power. London: Arnold.

Fairclough, N. (2003) Analysing Discourse: Textual Analysis for Social Research. London: Routledge.

Fairclough, N. (2015) Language and Power. New York: Routledge.

Halliday, M. A. K. (1985) An Introduction to Functional Grammar. London: Edward Arnold.

Halliday, M. A. K. (1994) An Introduction to Functional Grammar. London: Edward Arnold.

Halliday, M. A. K. and Matthiesen, C. (2004) An Introduction to Functional Grammar. London: Arnold.

Huddleston, R. and Pullum, G. (2002) Cambridge Grammar of the English Language. Cambridge: Cambridge University Press.

Greenbaum, S. (1996) The Oxford English Grammar. Oxford: Oxford University Press.

Gries, S. (2013) Statistics for Linguistics with R. California: Degruyter Mouton.

Iwamoto, N. (2007) Modality and point of view in media discourse. Retrieved on 20 February 2019 from human.kanagawa-u.ac.jp/gakkai/publ/pdf/no163/16308.pdf

Jordan, R. (1999) Academic Writing Course: Study Skills in English. Essex: Longman.

Kuchler, J. (2015) 'Usages of may and will in Chinese and German student papers: A corpus-based comparison.' In: Schmied, J. (ed.) Academic Writing for South Eastern Europe: Practical and Theoretical Pperspectives. Research in English and Applied Linguistics (REAL Studises) 8. 99-118.

Lihua, L. (2009) 'Discourse construction of social power: Interpersonal rhetoric in the editorials of China Daily.' Discourse Studies 11(1), 59-78.

Lillian, D. L. (2008) 'Modality, persuasion and manipulation in Canadian conservative discourse.' Critical Approaches to Conservative Discourses Across Disciplines 2(1), $1-16$.

Milkovich, S. and Sitarica, A. (2017) 'Epistemic modality in political discourse.' Social Studies and Humanities 3(1), 75-79.

Nartey, M. and Yamkson, F. (2014) 'A semantic investigation into the use of modal auxiliary verbs in the manifesto of a Ghanaian political party.' International Journal of Humanities and Social Sciences 4(3), 21-30.

Ngula, R. S. (2017) 'Epistemic modal verbs in research articles written by Ghanaian and international scholars: A corpus-based study of three disciplines.' Brno Studies in English 43(2), 5-27.

Nuyts, J. (2006) 'Modality: Overview and linguistic issues.' In: Frawley, W. (ed.) The Expression of Modality. Berlin: Mouton. 1-26.

Nwankwo, B., Ocheni, S. and Atakpa, M. (2012) 'A review of the military contributions to social transformation in Nigeria, 1966-1996.' Journal of Arts, Science and Commerce $3(2), 24-32$.

Olaniyan, K. and Adeniji, A. (2015) 'Modality in statement of objectives in arts-based research article abstracts.' British Journal of English Linguistics 3(1), 42-51.

Opeibi, T. (2015) 'New media and the transformation of political cultures in Nigeria: Exploring a corpus-based discourse approach.’ In: Opeibi, T., Schmied, J., Omoniyi, T. 
and Adedeji, K., (eds) Essays on Language in Societal Transformation. Research in English and Applied Linguistics (REAL Studises) 9. Göttingen: Cuvillier. 209-231.

Opeibi, B. (2016) 'Digital media and civic engagement in Nigeria: A corpus-based discourse study of President Goodluck Ebele Jonathan's Facebook.' In: Taiwo, R. and Opeibi, T. (eds) The Discourse of Digital Civic Engagement: Perspectives from the Developing World. New York: Nova Publishers. 1-34.

Oyebamiji, M. (2013) A critical stylistic analysis of selected advocacy campaigns on Nigerian Television Authority. Unpublished M. A. Thesis. Department of English, Ile-Ife: Obafemi Awolowo University.

Palmer, F. R. (2001) Mood and Modality. Cambridge: Cambridge University Press.

Papafragou, A. (2006) 'Epistemic modality and truth conditions.' Lingua 116, 1688-1702.

Partington, A. (2003) The Linguistics of Political Argument: The Spin-doctor and the Wolf-Pack at the White House. London and New York: Routledge.

Raphael, O. J. (2014) 'Religion, national transformation and the Nigerian society: Some reflections.' International Journal of Gender and Women's Studies 2(2), 117-136.

Resta, S. (1998) 'Words and social change. The impact of power and ideology on the language of Economics and Law.' ASP 19-22, 89-98.

Rui, Z. and Jingxia, L. (2018) 'The study of interpersonal meanings of modality in micro-blogging news discourse by the case of Donald Trump's Muslim entry ban.' Advances in Language and Literary Studies 9(2), 110-118.

Saale, L. B. (2014) 'Prayer and social transformation in Nigeria: A Christian perspective.' African Research Review 8(4), 111-124.

Vázquez Orta, I. (2010) 'A contrastive analysis of the use of modal verbs in the expression of epistemic stance in Business Management research articles in English and Spanish.' Iberica 19, 77-96.

Verschueren, J. (1999) Understanding Pragmatics. London: Edward Arnold.

Vukovic, M. (2014) 'Strong epistemic modality in parliamentary discourse.' Open Linguistics 1, 37-52.

Winiharti, M. (2012) 'The difference between modal verbs in deontic and epistemic modality.' Humaniora 3(2), 532-539.

Mohammed Ademilokun is a Senior Lecturer at Obafemi Awolowo University, Ile-Ife, Nigeria. He specialises in Discourse Analysis and has published articles in reputable journals such as Discourse and Communication, Discourse, Context and Media, Ghana Journal of Linguistics, Ibadan Journal of English Studies, International Journal of Society, Culture and Language, among others.

Address: Mohammed Ademilokun, Department of English, Obafemi Awolowo University, Ile-Ife, Osun 220282, Nigeria. [e-mail: mohmilokun@yahoo.com] 